\title{
Integration of Infrastructure and Process for Enhancement of the Research Mission of the University of Missouri
}

\author{
James English \\ Professor, Division of Plant Sciences, University of Missouri
}

mong the unique strengths of any research university is a community of
faculty members highly skilled and motivated in their scholarly pursuits.
Any research community is highly diverse both in areas of scholarship and approaches to investigation. Many members of the research community also contribute significantly to the education and training of undergraduate and graduate students in classroom and laboratory settings. At the University of Missouri (or, as known locally, MU), the research and teaching missions include more than 1,900 faculty and instructors associated with 286 degree programs.

To the general public and perhaps many members of a university itself, the community of research and teaching faculty can appear as chaotic as a field of stars in a desert sky. Ideally, however, there is organization within this community that optimizes the success of the university research mission. The basis for success of the mission is effective integration of institutional resources including infrastructure (both physical and human) and support processes.

The perspectives of resource integration at MU that I present here come from two sources, the first being 20 years of my own research endeavors as a microbiologist and plant scientist. The second source is my association with faculty from many disciplines on the MU campus through five years of involvement with the university Research Council. For the last two years, I have overseen the functions of the council (as Faculty Fellow for the Office of Research) that will be described later.

Integration of supportive resources is challenging within the complex research environment of $\mathrm{MU}$ or any similar university. Each faculty member has a unique professional history in terms of research training and experience. Additionally, each faculty member pursues research within a discipline-specific culture and with a propensity to work individually or as part of larger teams.

A basis for integration and management of institutional resources to accommodate disciplinary, cultural and personal diversity may be discovered by examining the day-to-day activities of research faculty. For example, on any particular day a faculty member invests time in management of research staff and training of undergraduate and graduate students. Additional time is given to assessment of research progress 
for one or more projects, development of various manuscripts for publication or presentations for conferences, and preparation of new grant applications. Increasingly greater amounts of time are also given to grant administration activities such as budget management, reporting to funding agencies, and management of compliance issues.

Institutional support for these daily activities is provided at MU in a variety of ways at multiple administrative levels. At the most local level, support comes from faculty peers in a department or college. These peers often provide critical feedback on research questions and advise on grant administration issues. Input from peer faculty can be informal, in the format of hallway or coffee shop discussions, or obtained more formally through mentoring committees as assigned by a department chairperson.

Also at a local level, the department chairperson and administrative staff are central to sustained research progress of faculty. For example, the chairperson coordinates, if not provides, the start-up resources needed to launch new faculty hires towards early research success. In many departments, annual discussions between the chairperson and individual faculty members assist in development of a mutual understanding of research progress and insight into needs for additional or modified support resources. Finally, the department chairperson is responsible for the development and management of administrative staff in providing effective service in the support of research activities.
At a more regional level, the administrative staffs of individual colleges remain central to faculty research success. An efficiently coordinated business office, in particular, is useful for simplifying many of the daily tasks performed by faculty in managing their research programs. Beyond administrative support, some colleges at MU historically provided limited funding on a competitive basis to support new and innovative research activities. Although these resources have become increasingly scarce within many colleges, funds are still provided through program centers within specific research disciplines.

Although physically far removed from most research laboratories and offices, the MU Office of Research plays a very central role in the daily lives of faculty. This office is responsible for creating, maintaining, and nurturing an array of resources in service to the university research mission. Among the Office's responsibilities is grant management through sponsored programs administration, oversight and support of research cores and centers, grant writing support, management of technologies and intellectual property, assistance in research compliance, management of undergraduate research training opportunities and finally, support of internal grant opportunities for faculty via Research Council.

Although all aspects of the Office of Research operations are important, I will focus here on the contributions of the MU Research Council and Research Cores and Centers in supporting faculty research. The Research Council manages 
funds that are allocated to support faculty through four competitive programs that include traditional research grants, international travel, research leave, and summer research fellowships. Research grants are funded at a maximum level of $\$ 7,500$ for a period of one year. These funds, though modest, have proven critical to faculty who are developing preliminary data for external grant submission, faculty who require bridge funding for research personnel, or who are completing data collection for final publication efforts. Travel grants of $\$ 1,500$ are provided to faculty members who make major presentations at international conferences or who are involved in conference organizing activities. Travel support is critical not only to international visibility of the faculty member but also to the visibility of MU. Research leave provides teaching replacement costs for faculty for a period of one year. The funds are particularly important for freeing faculty from heavy teaching loads to allow collection of data for ongoing projects, to finalize publishing of a major book project, or for exploring new research directions through interactions with colleagues at MU or at other institutions. Summer research fellowships provide two months of salary support for faculty to pursue research activities in a way similar to research leave support.

The Research Council annually reviews well over 200 proposals and allocates more than $\$ 600,000$ through these four programs. Last year, more than 190 faculty members received support for research-related activities. In my role as Faculty Fellow, I am responsible for oversight of the Council and its deliberations. Proposals are received from faculty in all schools, colleges and professional programs on campus. Proposals are reviewed in much the same way as they would be reviewed at NIH, NSF and other federal science agencies. The diversity of applicants requires a similarly diverse council membership. Consequently, the Council has grown over the years to include 28 faculty members representing the array of campus research disciplines.

For multiple reasons the importance of Research Council to the MU academic community will likely increase over time. First and foremost is the increasing competitiveness of external grant programs. In addition, changing priorities of some federal programs has led to reduced external funding opportunities for specific scientific disciplines.

The research cores and centers supported by the Office of Research play increasingly important roles in the success the campus research mission. The cores and centers serve the research community by providing expensive equipment and expert technical personnel that would be difficult to develop by individual research faculty or by individual departments. The nine cores supported by the Office of research include the Cell and Immunology Core, DNA Core, Electron Microscopy Core, Molecular Cytology Core, Nuclear Magnetic Resonance Core, Proteomics Core, Informatics Research Core, Structural Biology Core, and Transgenic Animal Core. These research cores provide equipment and services not only to MU faculty but to faculty from 
other academic institutions and commercial enterprises.

The cores are complemented by additional equipment and personnel resources at research centers across the MU campus. Among these are the MU Research Reactor, the Dalton Cardiovascular Research Center, the Christopher S. Bond Life Sciences Center, the International Institute of Nano and Molecular Medicine, the UM Bioinformatics Consortium, the Health Activity Center, the Interdisciplinary Center on Aging, and the Center for Arts and Sciences. University cores and centers will increase in their importance over time as scientific inquiry into the complexity of the world and universe becomes more sophisticated and more technically demanding.
At each of these hierarchical levels of research support at MU, there is a need to constantly assess the quality of resources directed to sustaining and enhancing the research mission and of any needs for enhancement. The means by which these assessments are made vary by specific administrative level and across institutional boundaries. In the Office of Research, annual evaluations of the office's Master Plan for Research and Technology Development are made to ensure that the immediate and future needs of the research community are being met. The degree of awareness by research faculty of efforts to integrate resources to support individual research programs is likely variable and may or may not be inconsequential to success of the research mission. 